\title{
Metabolic effects in mice of cream formulation: Addition of both thickener and emulsifier does not alter lipid metabolism but modulates mucus cells and intestinal endoplasmic reticulum stress
}

\author{
M. Milard, ${ }^{*}$ F. Laugerette, ${ }^{*}$ S. Bugeat, $†$ P. Plaisancié, ${ }^{*}$ M. Létisse, ${ }^{*}$ E. Meugnier, $\ddagger$ E. Loizon, $\ddagger$ A. Durand, ${ }^{*}$ \\ C. Buisson, ${ }^{*}$ A. Géloën, ${ }^{*}$ S. Serieye, $\dagger$ and M.-C. Michalski ${ }^{* 1}$ \\ *Univ Lyon, CarMeN Laboratory, INSERM, INRA, Université Claude Bernard Lyon-1, INSA Lyon; 69621 Villeurbanne, France \\ †Sodiaal International Research and Innovation Department, Paris, France \\ fUniv Lyon, CarMeN Laboratory, INSERM, INRA, Université Claude Bernard Lyon-1, INSA Lyon, 69600 Oullins, France
}

\begin{abstract}
Additives stabilize or improve the organoleptic or functional properties (or both) of many dairy products including whipping cream. Their influence on the metabolic effect of dairy cream is scarcely known. We tested the hypothesis that added emulsifier (lactic acid esters of mono- and diglycerides; MAG/DAG), thickener (carrageenan, CGN), or both, could modify the metabolic effect, notably in the intestine and liver. Nine-week-old male $\mathrm{C} 57 \mathrm{Bl} / 6 \mathrm{~J}$ mice were fed UHT cream (indirect treatment) mixed with nonlipidic powder (final: $13 \%$ milkfat) for 1 or 4 wk. We compared creams (1) without additive (Ctl), (2) with thickener (Th), $0.02 \%$ of $\kappa-C G N$, and (3) with both thickener and emulsifier, $0.1 \%$ of MAG/DAG esters (Th/Em). We analyzed plasma parameters, intestine, and liver. Fasting glycemia, insulinemia, triglyceridemia, nonesterified fatty acids, body weight gain, and liver weight did not differ among groups. After $1 \mathrm{wk}$, Th/Em had higher expression in the duodenum of some of the genes involved in (1) intestinal lipid absorption and (2) tight junction proteins versus Ctl and Th. After 4 wk, mucus cell number in the small intestine was higher in $\mathrm{Th} / \mathrm{Em}$ versus $\mathrm{Ctl}$ and Th. Genes involved in endoplasmic reticulum (ER) stress in the duodenum were more expressed in Th/Em after 1 wk. After 4 wk, in the colon, a higher expression of ER stress genes was observed for Th versus Th/Em and Ctl. Liver damage score was not altered by additives. Adding both CGN (0.02\%) and MAG/ DAG esters $(0.1 \%)$ in dairy cream did not result in deleterious outcomes in mice after 4 wk regarding lipid metabolism, intestinal permeability, and liver disorders.
\end{abstract}

Received March 20, 2018.

Accepted August 21, 2018.

${ }^{1}$ Corresponding author: marie-caroline.michalski@inra.fr
The longer term effect of intestinal ER stress modulation deserves further investigation.

Key words: nutrition, dairy matrix, cow milk, carrageenan

\section{INTRODUCTION}

Food additives, commonly added in dairy creams to preserve their organoleptic and functional properties, are an essential part in the optimization of industrial processes and formulation. In this respect, low molecular weight emulsifiers, most often mono- and diglycerides (MAG/DAG) and their esters and nondairy stabilizers (alginates, carrageenans, gums, and gelatins), are used in many dairy products. Therefore, different studies examined the effect of these additives on the rheological properties of final products (Lal et al., 2006; Arltoft et al., 2007).

Among stabilizers, carrageenans (CGN) are natural substances derived from red algae. Carrageenans are often incorporated into a wide variety of food products (denoted E-407 by the European Food Safety Authority; Burges Watson, 2008), notably to improve food texture and solubility (Bhattacharyya et al., 2008). However, safety of CGN is a topic of intense controversy: a recent review discussed CGN characteristics and digestive fate in this context (David et al., 2018). A degradation product of CGN (namely poligeenan) has been shown to cause gastrointestinal troubles such as colitis and cecal response in rats (Engster and Abraham, 1976; Tobacman, 2001; Benard et al., 2010). Several studies have shown promoting effects of CGN on colon cancer (Watanabe et al., 1978; Arakawa et al., $1986,1988)$. The CGN also promoted the occurrence of aberrant crypt in rat colon at a dose of 0.25 and $2.5 \%$ with azoxymethane injection (Corpet et al., 1997). Regarding intestinal metabolism, a recent in vitro study has demonstrated the effect of CGN on decreased gastric proteolysis and altered gut epithelial structure 
and function. Carrageenan induced an alteration of epithelial barrier function, including redistribution of the tight-junction protein zonula occludens (ZO)-1, increased monolayer permeability, and elevated levels of the pro-inflammatory IL-8 receptor (Borthakur et al., 2007; Fahoum et al., 2017).

Parallel to stabilizers, emulsifiers are also widely used by the food industry to stabilize oil-in-water emulsions, notably MAG/DAG and their esters. The latter are synthetic lipids from glycerol and natural fatty acids derived from animal fats (pig, beef) or vegetables (soy, maize, and rapeseed); these food additives are used to stabilize water/lipid interfaces of edible oils and fats due to their amphiphilic structure and good emulsifying properties. In the United States, MAG/DAG emulsifiers represent approximately $70 \%$ of total emulsifiers used in food products (Kamel, 1991). Recent studies revealed that other stabilizers/emulsifiers (carboxymethylcellulose and polysorbate-80) altered gut microbiota and mucus-bacteria interactions in the colon (Chassaing et al., 2015). Moreover, epidemiological studies report that the increased use of these emulsifiers in the agri-food industry is correlated with the increased incidence of colon cancer or inflammatory bowel disease (Viennois et al., 2017).

Until recently, major studies on the effect of dairy products on cardiometabolic health consisted mostly of epidemiological or randomized controlled trial studies about the differential health effects of different dairy matrixes (e.g., yogurt vs. cheese vs. butter, low-fat vs. high fat; de Oliveira Otto et al., 2012; Drouin-Chartier et al., 2016a,b; Lovegrove and Givens, 2016; Thorning et al., 2016, 2017). Altogether, the authors suggest that the supposed deleterious effects of SFA on cardiometabolic risk would be "cancelled" when the latter are consumed as part of a complex matrix such as in cheese and dairy products in general. Regarding cream consumption in humans, in a recent randomized controlled trial, volunteers consumed $\sim 41 \mathrm{~g}$ of milkfat per day incorporated in a muffin as whipping cream or as anhydrous milkfat for 8 wk. Anhydrous milkfat-in-muffin diet increased total and low-density lipoprotein cholesterol plasma concentrations, whereas whipping-cream-in-muffin diet did not exert such an effect (Rosqvist et al., 2015). This suggested a most beneficial effect of dairy cream, probably at least partly due to its milk phospholipid content via the milk fat globule membrane (Rosqvist et al., 2015). Moreover, the metabolic effect of cream from pasture-fed cows was found more favorable than that from corn silage in mice (Benoit et al., 2014).

However, to date, no studies have investigated the metabolic effect of dairy UHT cream formulation, no- tably regarding the use of CGN, emulsifier, or both. In a companion study (Milard et al., 2018), we showed that the type of UHT process applied to a cream with CGN differentially affected metabolic parameters in mice after a 4-wk fat-rich diet, partly due to cream structure. Here we studied the intestinal and metabolic effect of cream treated with indirect UHT treatment according to its formulation: (1) without additives (Ctl) or (2) with CGN $(0.02 \%$, Th) alone, or (3) also with MAG/DAG ester emulsifier $(0.1 \%, \mathbf{T h} / \mathbf{E m})$. The dose of additives in the present study was similar to the concentrations found in commercially made creams. We focused on lipemia and related organs (small intestine, liver), and on the gut permeability by counting the number of mucus cells and analyzing the gene expression of some tight junction proteins. The effect of the different diets on the endoplasmic reticulum (ER) stress was also analyzed.

\section{MATERIALS AND METHODS}

\section{Animals and Experimental Protocols}

This study is part of a wider animal and experimental design aiming to explore the effect of cream heat treatment and additives, which is described in the companion paper (Milard et al., 2018). Animal experiments were carried out in accordance with the Guiding Principles for the Care and Use of Vertebrate Animals in Research and Training and the French Ministère de l'Agriculture (no. 87-848 completed by no. 2001-464) and EU Council Directive for the Care and Use of Laboratory Animals (no. 2010/63/EU). The experimental protocol was approved by the Animal Ethics Committee of INSA-Lyon. Male C57Bl6/J mice (9 wk old) were fed for 1 or $4 \mathrm{wk}(\mathrm{n}=10$ in each group, 5 mice per cage). At the end of the experiment, fasted mice were euthanized by intraperitoneal injection of urethane and blood was collected by cardiac puncture on heparincontaining tubes. Small intestine, colon, liver, and epididymal adipose tissue (EAT) were collected and stored at $-80^{\circ} \mathrm{C}$ until analyses.

\section{Diets}

The 3 UHT creams (sterilized with indirect treatment, $35 \mathrm{wt} \%$ fat) differing in additive contents studied here (Table 1) were indirect UHT processed cream without thickener or emulsifier (Ctl); indirect UHT processed cream with thickener $(\mathbf{T h}): 0.02 \%$ of $\kappa$-CGN (Danisco, Copenhagen, Denmark); and indirect UHT processed cream with both thickener and emulsifier (Th/Em): $0.1 \%$ of MAG/DAG esters (Lactem, lactic 
acid esters of MAG/DAG, Danisco) and 0.02\% א-CGN (the same as in Th cream). The fatty acids in Lactem are palmitic and stearic acids.

Of note, the Th group is the same as in our other study on the effect of the type of UHT process applied to cream (Milard et al., 2018). All creams (SodiaalCandia, La Talaudière, France) were prepared from the same milk batch therefore only differing by their additives. We designed the diets in order (1) to provide mice a complete moderately high-fat diet in which all lipids are those from cream, (2) while not altering cream structure that would be induced by a classical solid pellets production, but (3) by avoiding a daily gavage with creams for several days that would stress mice and induce bias in studies of metabolic outcomes. To this aim, as previously recommended to preserve the lipid structure (Oosting et al., 2014), diets were not pelletized but given to the mice as dough (creams mixed with nonlipidic powder). The lipid content of each diet was $13.2 \%$. The alipidic powder was purchased from SAFE (Augy, France).

\section{Biochemical Analyses of Plasma}

Different plasma parameters were assessed in mice (fasted overnight). Glycemia, insulinemia, and plasma concentration of triglycerides (TG) and nonesterified fatty acids (NEFA) were measured according to the recommendations of the supplier of commercial kits. Concentrations of glucose was performed after tail vein incision and measured by MyLife PuraX blood glucose meter (MyLife, New Delhi, India). For mice that were fed diets for $1 \mathrm{wk}$, we measured insulinemia with Mouse Ultrasensitive Insulin ELISA (Eurobio, Alpco, Les Ulis,

Table 1. Composition of the experimental $\operatorname{diets}^{1}$

\begin{tabular}{|c|c|c|c|}
\hline Ingredient ( $\mathrm{g} / 100 \mathrm{~g}$ of diet) & $\mathrm{Ctl}$ & Th & $\mathrm{Th} / \mathrm{Em}$ \\
\hline Dairy cream & 37.8 & 37.8 & 37.8 \\
\hline Total dry extract & 15.1 & 15.1 & 15.1 \\
\hline Lipids & 13.2 & 13.2 & 13.2 \\
\hline Defatted DM & 1.9 & 1.9 & 1.9 \\
\hline Water & 22.7 & 22.7 & 22.7 \\
\hline \multicolumn{4}{|l|}{ Additives } \\
\hline к-CGN & - & 0.008 & 0.008 \\
\hline MAG/DAG esters & - & - & 0.04 \\
\hline Alipidic power & 62.2 & 62.2 & 62.2 \\
\hline Dextrose & 28.0 & 28.0 & 28.0 \\
\hline Cellulose & 5.6 & 5.6 & 5.6 \\
\hline Vitamin mixture & 6.5 & 6.5 & 6.5 \\
\hline Mineral mixture & 0.9 & 0.9 & 0.9 \\
\hline Alipidic casein & 21.2 & 21.2 & 21.2 \\
\hline
\end{tabular}

France), and for mice fed for $4 \mathrm{wk}$, using Ultrasensitive Mouse Insulin ELISA kit (Crystal Chem, Zaandam, the Netherlands; different kits for 1 and 4 wk for practical reasons due to kit availability). Plasma TG concentration was determined by colorimetric method (Triglyceride PAP 150 kit, bioMérieux, Marcy l'Etoile, France). Plasma NEFA concentration was measured using NEFA-C kit (Wako Chemicals, Richmond, VA).

\section{Histological Examination of Intestine for Goblet Cell Determination and Liver Damage}

Imaging experiments were performed on the Cell Station of CellImaP platform (IFR100, Dijon, France). Paraffin sections were rehydrated and prepared as previously described (Milard et al., 2018). To count the number of goblet cells, sections were stained with Alcian blue and periodic acid-Schiff's reagent to visualize the total mucins. The intestinal epithelium (duodenum, jejunum, and ileum) was analyzed by assessing the number of goblet cells per crypt-villus axis. Livers were stained with hematoxylin and eosin and were examined to determine liver damage score as previously described (Milard et al., 2018).

\section{Tissue RNA Extraction and Real-Time Quantitative PCR}

Total RNA was extracted from whole intestine segments (duodenum and colon) of mice with TRI Reageant (Sigma, Saint-Quentin-Fallavier, France). The concentration of RNA was measured with NanodropND1000 (Labtech, Healthfield, East Sussex, UK), and RNA samples with A260/240 ration between 1.7 and 2.1 were considered of good quality. One microgram of RNA was used for target gene expression using real-time quantitative PCR. TATA-box-binding protein (TBP) expressions were used as internal standard for normalization of target mRNA expression. The list of the PCR primers used is shown in Supplemental Table S1 (https://doi.org/10.3168/jds.2018-14783).

\section{Measurement of Fecal Fatty Acid Content}

Feces of mice were collected at the end of the experiment in the cage. Feces fatty acid profiles were analyzed by GC as previously described (Milard et al., 2018).

\section{Physicochemical Parameters of UHT Cream}

Fat droplet size distribution was analyzed by a laser particle size analyzer (Malvern Mastersizer 2000, Worcestershire, UK; static light scattering); to inhibit 
flocculation, $19 \mathrm{~mL}$ of a $10 \mathrm{~g} / \mathrm{L}$ SDS solution was added to $1 \mathrm{~mL}$ of cream. Obscuration was set between 5 and $7 \%$ and the recorded value was the volume weighted average diameter $d_{4,3}$. The flocculation index was calculated by dividing the $\mathrm{d}_{4,3}$ of the cream diluted with water by the $d_{4,3}$ of the cream with the addition of SDS. The whipping ability was measured by a RM8 Robotcoupe (Robotcoupe, Vincennes, France) at speed 7 for 4 min. Viscosity was measured at $4^{\circ} \mathrm{C}$ by a Brookfield DV-I Prime (Brookfield, Middleboro, MA), with the modulus 62 and a speed of 10. Firmness was measured by penetrometry on a Brookfield CT-3 TA. The probe (TA4-1000) penetrated into the sample for $3 \mathrm{~mm}$ at a speed rate of $1 \mathrm{~mm} / \mathrm{s}$, the force needed to reach this depth was resumed as firmness. The value was calculated as a mean of 3 sample measurements. The sample preparation led to fill a cylinder bowl (diameter $7 \mathrm{~cm}$ ) with foamed cream while avoiding insertion of big air domains.

\section{Statistical Analysis}

Correlation, principal component analysis, and normality test were performed using the computing environment R (R Development Core Team, R Foundation for Statistical Computing, Vienna, Austria), and principal component analysis was performed on normalized data. Normality of data was examined using the Shapiro-Wilk test with the computing $\mathrm{R}$ environment. Variance homogeneity was examined by using Bartlett's test and Brown Forsythe. The statistical significance of the difference between mean values was assessed (1) for normally distributed data, by 1-way ANOVA followed by a Tukey post-hoc multiple comparisons test, and (2) for nonnormally distributed data or data with small number of observations, by Kruskal-Wallis test followed by a Dunn post hoc test. Analyses were performed using GraphPad Prism software (GraphPad, San Diego, CA). Results were expressed as the mean value \pm standard error of the mean. Significance for statistical tests was set at $P<0.05$.

\section{RESULTS}

\section{Principal Component Analyses}

The first 2 components of the principal component analyses represented $52.7 \%$ of variance (Figure 1) and reveal differential metabolic effects between groups. Notably, the Th/Em group exhibited mostly an effect on the number of mucus cells and on the expression of tight junction protein in the duodenum. Liver damage score was more associated with the Ctl group.

\section{Cream with Additives Did Not Alter Liver Damage Score}

Addition of emulsifier or thickener (or both) in UHT cream had no significant effect on food intake, weight gain, or EAT to BW ratio after 1 or 4 wk diets (Table 2 ). However, after $1 \mathrm{wk}$, the liver to $\mathrm{BW}$ ratio was lower with the group containing the thickener alone (Th) than the group containing both additives (Th/ Em; $P<0.05)$. However, the liver to BW ratio was similar among groups after 4 wk of diet. The liver of Th/Em mice exhibited less pronounced steatosis after 4 wk versus mice fed the Ctl cream (Figure 2). Fasting glycemia, insulinemia, TG, and NEFA were not significantly different between groups (Table 2). We also analyzed endotoxemia in plasma and the gene expression of some inflammatory markers in EAT: Cd14 (an endotoxin receptor), $L b p$ (a transporter of endotoxins), Il6 (a proinflammatory cytokine), Mcp1 (a chemokine promoting the recruitment of monocytes into macrophages), Tnfa (a proinflammatory cytokine), and Cd68 (a marker of macrophage infiltration). No differences were observed among groups after 4 wk (results not shown).

\section{Cream with Both CGN and MAG/DAG Esters Induced a Short-Term Regulation of Lipid Metabolism in the Small Intestine}

To evaluate if the differences observed in the liver to BW ratio and hepatic score could be due to a difference in lipid absorption mechanisms, we studied the gene expression of lipid absorption-related proteins in the proximal small intestine. In the duodenum, microsomal TG transfer protein ( $M t t p$; Figure 3A), involved in chylomicron production and secretion, was more expressed in the Th/Em group versus the 2 other groups after 1 wk of diet $(P<0.01$ versus Th group and $P<0.05$ versus $\mathrm{Ctl}$ group). An increase in gene expression of the fatty acid transport protein 4 (Fatp 4; Figure 3B) was observed in the Th/Em group compared with both others groups after 1 wk of $\operatorname{diet}(P<0.01$ versus Th and $P<0.05$ versus $\mathrm{Ctl}$ ). The fatty acid binding protein 2 (Fabp2; Figure 3C) was increased in the Th/Em group compared with both Th groups after 1 wk of diet $(P$ $<0.01$ ). Of note, a positive correlation was observed between the duodenal expression of Mttp and Fatp 4 (r $=0.76, P<0.001)$. However, after $4 \mathrm{wk}$, no significant difference in the expression of genes involved in lipid metabolism was observed among groups. The amount of fatty acids excreted in the feces differed according to additives present in cream. After $1 \mathrm{wk}$, the fatty acid loss was not significantly different among groups 


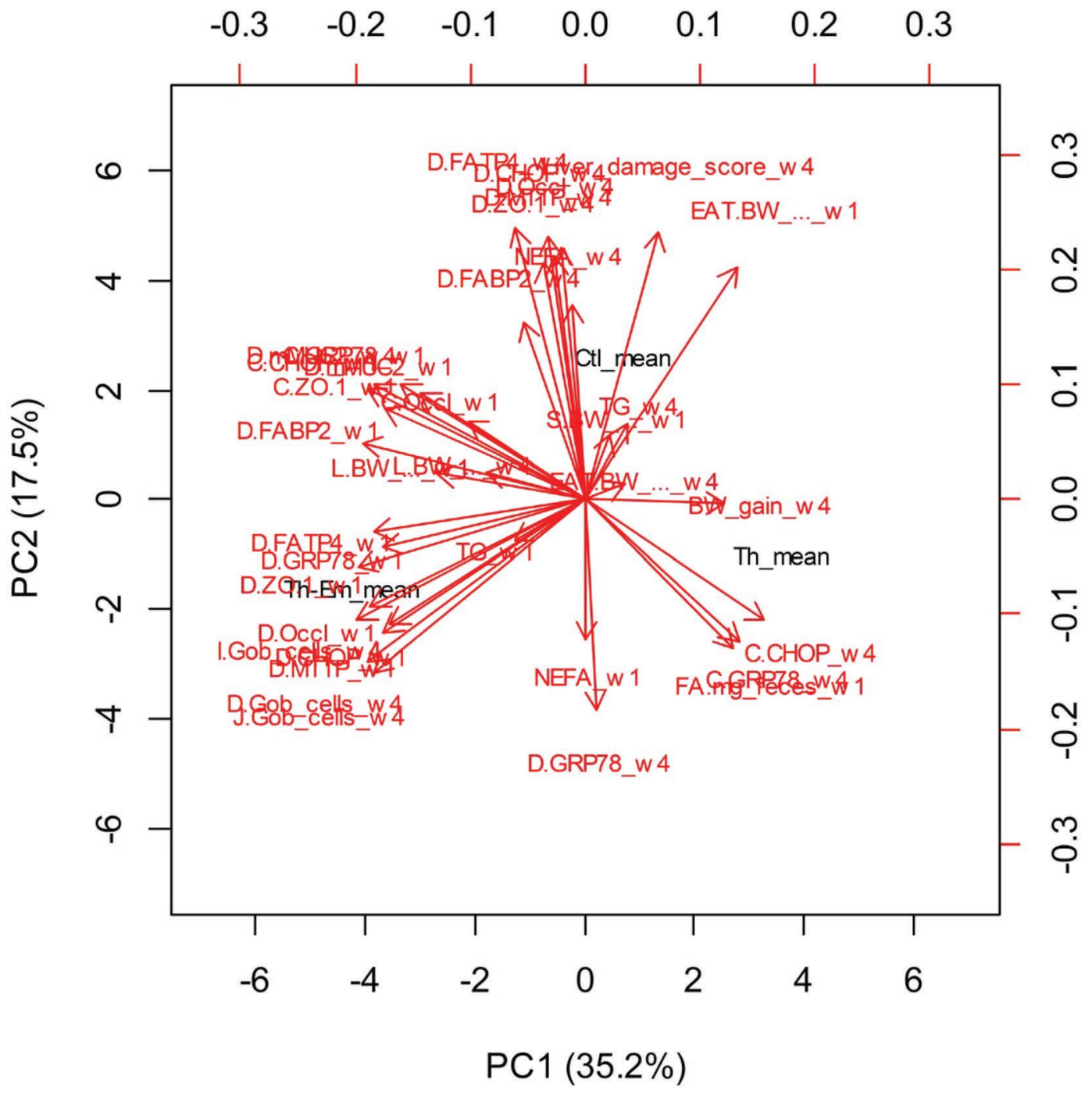

Figure 1. Principal component (PC) analysis of the various outcomes (in plasma and intestine) measured in mice fed diet with UHT cream for 1 or $4 \mathrm{wk}$. The Ctl group was fed a UHT cream without additives, the Th group was fed a UHT cream that contained $\kappa$-carrageenan ( $\kappa$-CGN; $0.02 \%$ ), and the Th/Em group was fed a UHT cream that contained $\kappa$-CGN $(0.02 \%)$ and lactic acid esters of mono- and diglycerides $(0.1 \%)$. The first 2 components representing $52.7 \%$ of the data are shown. D. Occl = occludin in the duodenum; C.GRP78 $=$ Grp 78 in the colon; $\mathrm{C} . \mathrm{CHOP}=$ Chop in the colon; D.ZO-1 = zonula-occluden-1 in the duodenum; D.mMuc2 = mucin-2 in the duodenum; D.MTTP $=$ microsomal TG transfer protein in the duodenum; D.FABP2 = fatty acid binding protein 2 in the duodenum; D.FATP $4=$ fatty acid transport protein 4 in the duodenum; EAT.BW = epididymal adipose tissue weight to BW ratio; FA.mg_feces = fecal lipids excretion; L.BW $=$ liver weight to BW ratio; Gob cells: number of mucus cells in the duodenum $(\mathrm{D})$, jejunum $(\mathrm{J})$, and ileum $(\mathrm{I})$; NEFA $=$ nonesterified fatty acids; TG $=$ triglycerides. Color version available online.

(Figure 3D), but tended to be higher in the Th versus Ctl group $(P=0.1)$. However, after $4 \mathrm{wk}$, the amount of fecal fatty acids was lower in the Th group compared with Th/Em group $(P<0.05)$.

\section{Cream with Both CGN and MAG/DAG Esters Increased the Number of Mucus Cells in the Small Intestine After 4 wk of Diet}

An in vitro study reported that CGN can alter the gut barrier and decrease the gene expression of the tight junction protein ZO-1 (Choi et al., 2012). Moreover, liver alterations have been related to gut barrier dysfunctions in vivo (Mir et al., 2016). To evaluate if the differences observed here in the hepatic score could be linked to a difference in the gut barrier function, we studied (1) the number of colonic goblet cells after $4 \mathrm{wk}$ in the small intestine (Figure $4 \mathrm{~A}-4 \mathrm{C}$ ) and (2) the gene expression of mucin-2 (Muc2; Figure 4E) and of 2 tight junction proteins (occludin and Zo1) in the duodenum after 1 and 4 wk (Figure $4 \mathrm{~F}-4 \mathrm{G}$ ). The number of mucus cells increased after $4 \mathrm{wk}$ in the Th/Em group compared 
Table 2. Biometric data and plasma concentration ${ }^{1}$ of glucose, insulin, triglycerides (TG), and nonesterified fatty acids (NEFA) in male C57Bl/6J mice fed diet with different UHT cream (sterilized by an indirect treatment) which differed by the addition of additives for 1 or 4 wk

\begin{tabular}{|c|c|c|c|c|c|c|}
\hline \multirow{2}{*}{ Item } & \multicolumn{6}{|c|}{ Diet group } \\
\hline & \multicolumn{3}{|c|}{$1 \mathrm{wk}$} & \multicolumn{3}{|c|}{$4 \mathrm{wk}$} \\
\hline \multicolumn{7}{|l|}{ Biometric data } \\
\hline Initial BW, g $(\mathrm{n}=10)$ & $21.4 \pm 0.4$ & $21.2 \pm 0.5$ & $22.3 \pm 0.6$ & $22.7 \pm 0.4$ & $23.0 \pm 0.5$ & $24.0 \pm 0.2$ \\
\hline BW gain, $\mathrm{g}$ & - & - & - & $5.4 \pm 0.5$ & $5.3 \pm 0.4$ & $4.2 \pm 0.3$ \\
\hline Food intake, $\mathrm{g} / \mathrm{d}$ & $3.9 \pm 0.2$ & $4.5 \pm 0.3$ & $4.3 \pm 0.5$ & $4.3 \pm 0.1$ & $4.4 \pm 0.08$ & $4.6 \pm 0.06$ \\
\hline \multicolumn{7}{|l|}{ Plasma concentration $^{2}$} \\
\hline Glucose, $\mathrm{mg} / \mathrm{dL}$ & $109.0 \pm 6.6$ & $122.7 \pm 10.8$ & $120.6 \pm 9.3$ & $120.7 \pm 5.7$ & $138.6 \pm 13.1$ & $129.4 \pm 7.8$ \\
\hline Insulin, mg/dL & $0.56 \pm 0.12$ & $0.66 \pm 0.19$ & $0.84 \pm 0.39$ & $0.23 \pm 0.11$ & $0.35 \pm 0.06$ & $0.40 \pm 0.11$ \\
\hline $\mathrm{TG}, \mathrm{mg} / \mathrm{mL}$ & $0.59 \pm 0.04$ & $0.53 \pm 0.04$ & $0.65 \pm 0.05$ & $0.52 \pm 0.02$ & $0.70 \pm 0.09$ & $0.57 \pm 0.06$ \\
\hline $\mathrm{NEFA}, \mathrm{mg} / \mathrm{dL}$ & $20.2 \pm 1.5$ & $19.2 \pm 1.5$ & $21.3 \pm 1.3$ & $24.5 \pm 1.6$ & $22.5 \pm 1.1$ & $22.2 \pm 1.7$ \\
\hline
\end{tabular}

${ }_{\mathrm{a}, \mathrm{b}}$ Means in a row without a common superscript letter differ, $P<0.05$.

${ }^{1}$ Values represent the mean \pm SEM. The numbers in parentheses represent the number $n$ of mice. For BW gain, $\mathrm{n}=7$ for Ctl and $\mathrm{n}=8$ for Th and Th/Em. For EAT to BW ratio, $n=9$ for Ctl and $n=10$ for Th and Th/Em. For liver to BW ratio, glucose, TG, nonesterified fatty acids, $\mathrm{n}=10$ except for Ctl group at $4 \mathrm{wk}, \mathrm{n}=9$. For insulin, for 1 wk of diet, $\mathrm{n}=9$ for Ctl, $\mathrm{n}=6$ for Th, and $\mathrm{n}=9$ for Th/Em. For 4 wk of diet, $\mathrm{n}=7$ for Ctl and Th group and $\mathrm{n}=6$ for Th/Em group. EAT $=$ epididymal white adipose tissue; Ctl $=$ UHT cream without additives; Th $=$ UHT cream with $\kappa$-carrageenan $(\kappa-\mathrm{CGN}) ; \mathrm{Th} / \mathrm{Em}=\mathrm{UHT}$ cream with $\kappa$-CGN and lactic acid esters of mono- and diglycerides.

${ }^{2}$ Measurements were performed on fasting plasma. NEFA $=$ nonesterified fatty acids.

with both other groups $(P<0.05$ in the duodenum and the ileon, $P<0.05$ versus the Th group and $P<0.01$ versus the $\mathrm{Ctl}$ group in the jejunum; $P=0.7 \mathrm{Th} / \mathrm{Em}$ vs. Th group and $P=0.5 \mathrm{Th} / \mathrm{Em}$ vs. Ctl group in the colon). After $1 \mathrm{wk}$ of diet, the Muc2 gene expression was decreased in Th group compared with Th/Em ( $P$ $<0.01$ ). The gene expression of Ocln (occludin) and Zo-1 in the duodenum was higher in the Th/Em group than in $\mathrm{Ctl}$ and Th groups after 1 wk of diet $(P<0.01)$.
No differences were observed in the other intestinal sections and after 4 wk of diet (data not shown).

\section{ER Stress Markers Were Differentially Affected by the Diets in Duodenum and Colon}

We also evaluated if the differential effect of creams on mucus cells and tight junction expression was associated with a different cell stress response. We analyzed
A

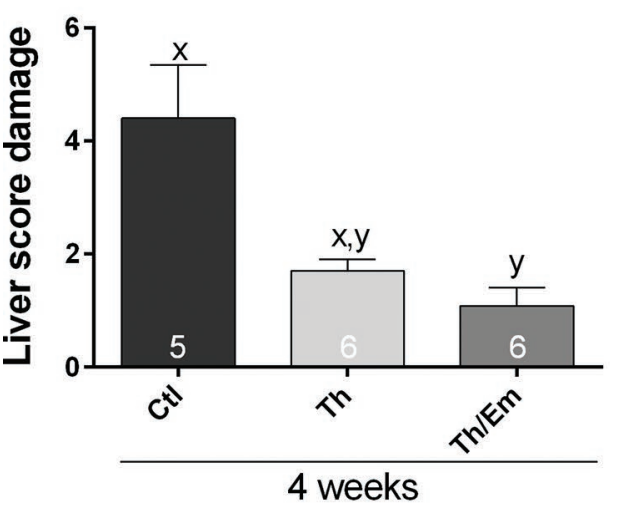

B

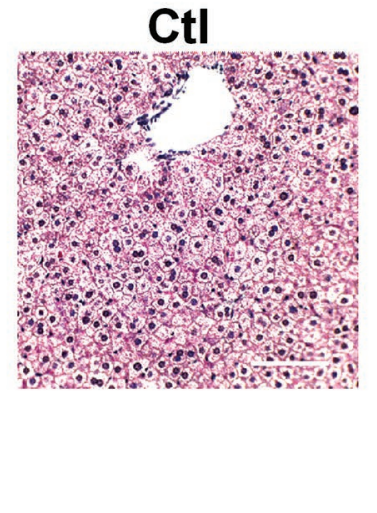

Th

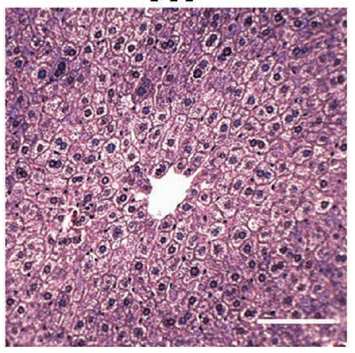

Th/Em

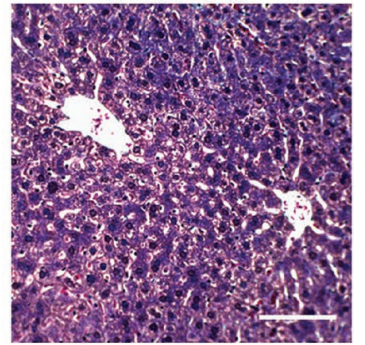

Figure 2. Effect of different UHT cream on the liver score damage in mice fed diet with UHT cream for 1 or 4 wk. The Ctl group was fed a UHT cream without additives; the Th group was fed a UHT cream that contained $\kappa$-carrageenan ( $\kappa$-CGN; 0.02\%), and the Th/Em group was fed a UHT cream that contained $\kappa$-CGN $(0.02 \%)$ and lactic acid esters of mono- and diglycerides (0.1\%). (A) Liver score damage. Values are means \pm SEM. Number of mice in each group is indicated within the bars. Means without a common letter differ $(P<0.05):(\mathrm{x}-\mathrm{z})$ after 4 wk of diet. (B) Hematoxylin and eosin-stained liver histological image typical of Ctl (left), Th (middle), and Th/Em (right) at 40× magnification. Scale bars $=100 \mu \mathrm{m}$. Color version available online. 
the expression of glucose-related protein precursor 78 (Grp78) and CCAAT-enhancer-binding protein homologous protein (Chop), 2 markers involved in ER stress, at the mRNA level by real-time quantitative PCR (Figure 5). After $1 \mathrm{wk}$ of diet, the group fed the cream containing both additives exhibited a higher Grp78 expression in the duodenum $(P<0.01)$ and the colon $(P<0.05)$ than Th group. After 4 wk of diets, no significant difference was observed. Chop was significantly higher in the duodenum of the Th/Em group after 1 wk of diet in comparison with the Th group ( $P$ $<0.05)$ and $\mathrm{Ctl}$ group $(P<0.01)$, but no difference was observed after 4 wk. In the colon, Chop gene expression was lower in the Th group than in both other groups after 1 wk $(P<0.0001)$, but was higher in the Th group after 4 wk $(P<0.0001)$.

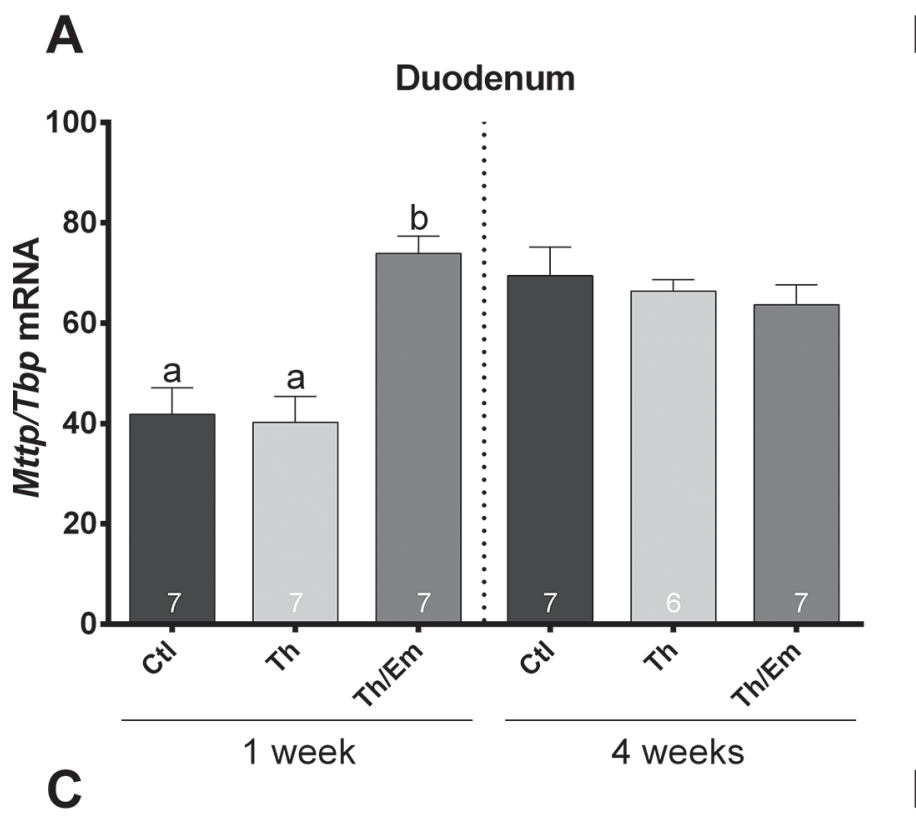

B
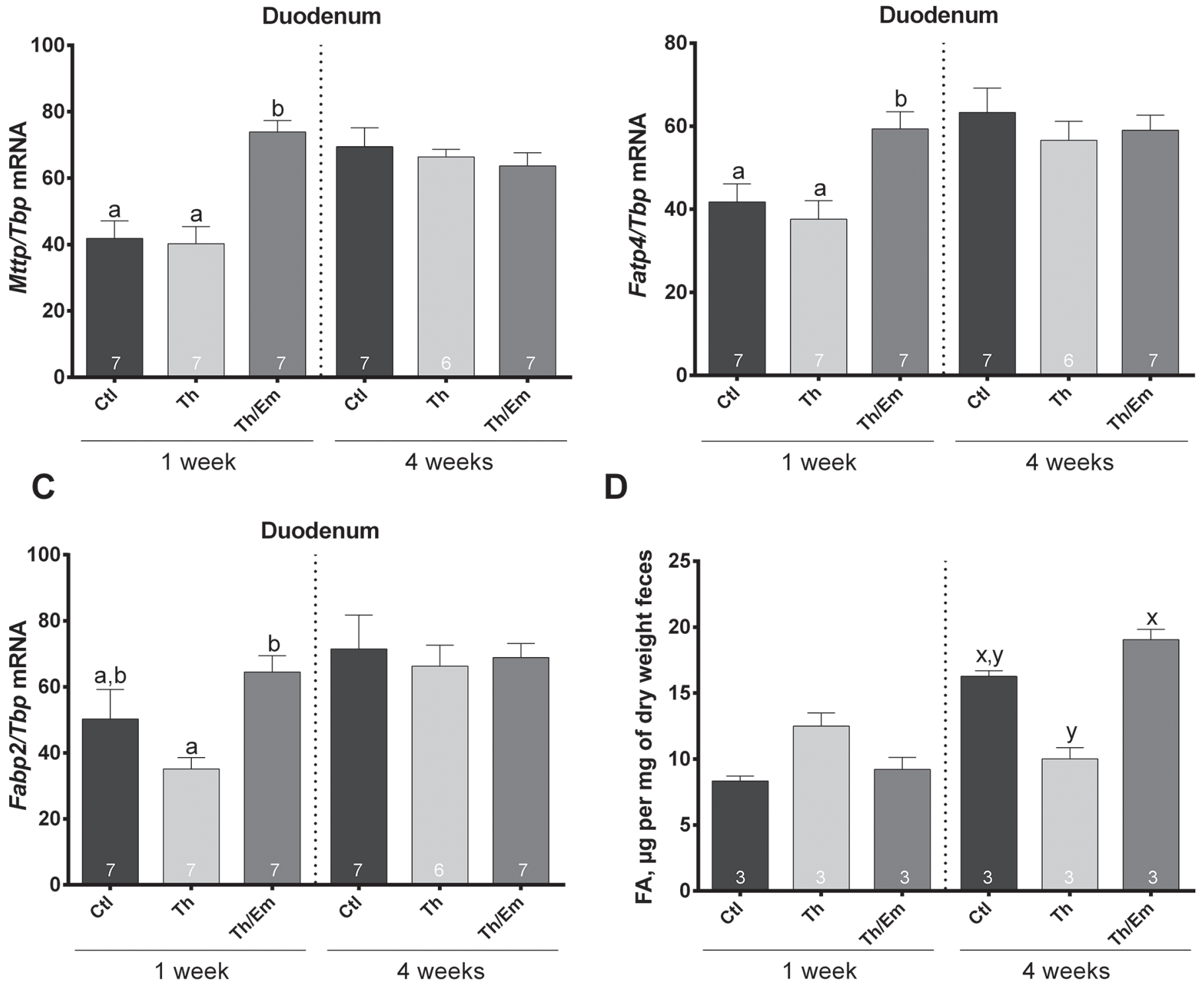

Figure 3. Change in expression of genes involved in lipid metabolism in the duodenum and effect on fecal lipid excretion from mice fed a diet with UHT cream for 1 or $4 \mathrm{wk}$. The Ctl group was fed a UHT cream without additives, the Th group was fed a UHT cream that contained $\kappa$-carrageenan ( $\kappa-C G N ; 0.02 \%$ ), and the Th/Em group was fed a UHT cream that contained $\kappa$-CGN (0.02\%) and lactic acid esters of mono- and diglycerides $(0.1 \%)$. The mRNA level of (A) microsomal TG transfer protein (Mttp), (B) fatty acid transport protein 4 (Fatp 4$)$, and (C) fatty acid binding protein 2 (Fabp2) in the duodenum. Values are normalized to the levels of TATA-binding protein (Tbp) mRNA. (D) Fecal lipids after 1 or 4 wk of diet. Number of $n$ in each group is indicated within the bars. Bars represent means \pm SEM. Means without a common letter differ $(P<0.05)$ : $(\mathrm{a}-\mathrm{c})$ after $1 \mathrm{wk}$ of diet, and $(\mathrm{x}-\mathrm{z})$ after $4 \mathrm{wk}$ of diet. FA $=$ fatty acid. 
A
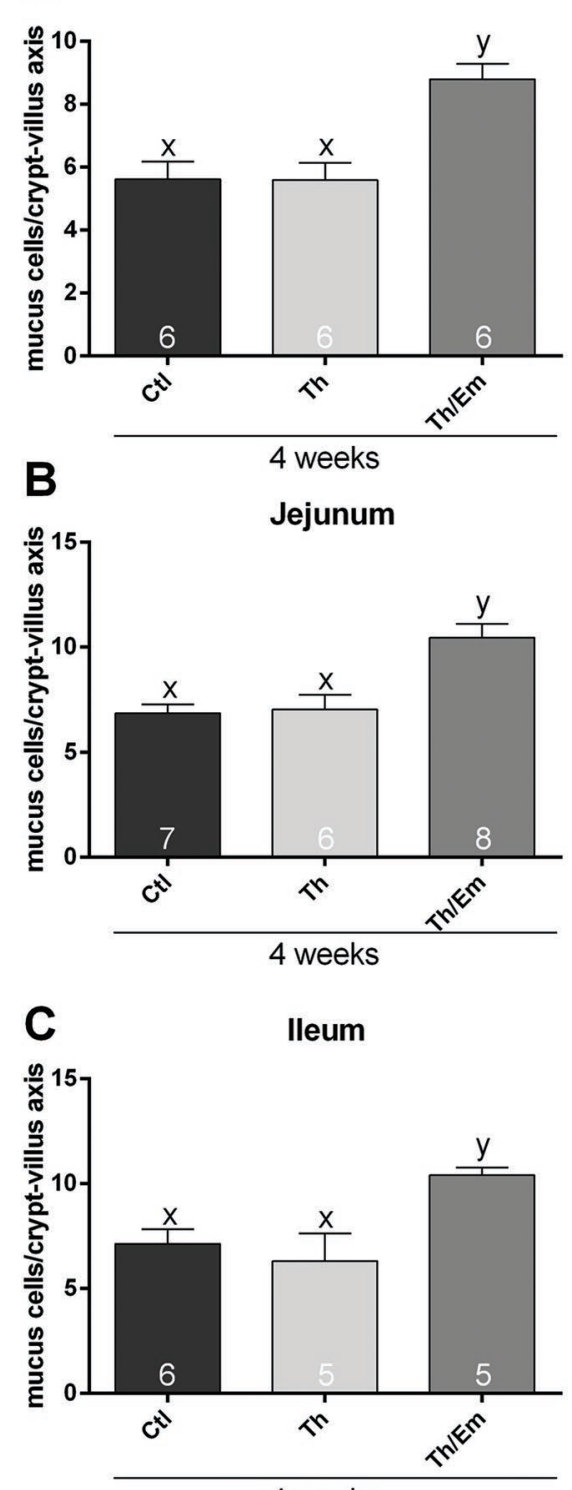

D

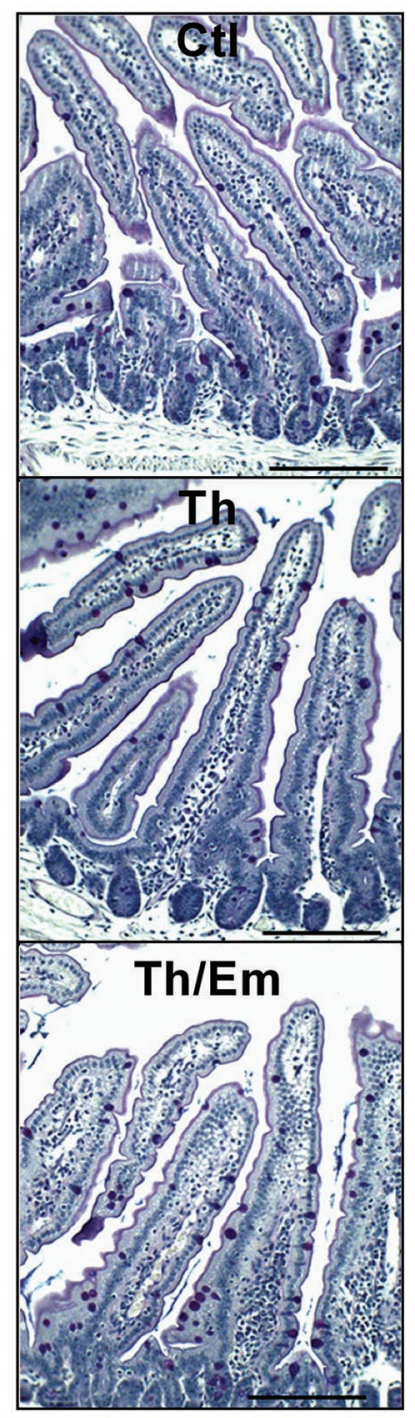

E

$\mathbf{F}$
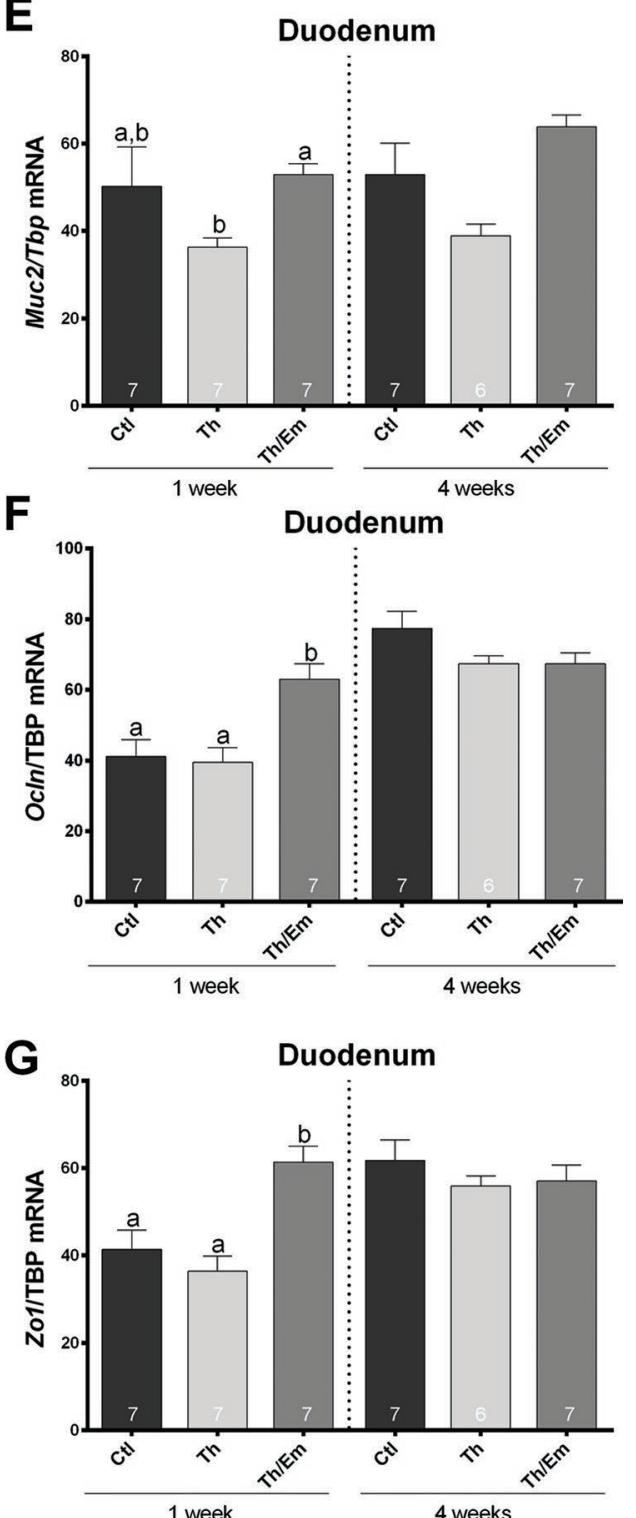

Figure 4. Change on intestinal barrier parameter from mice fed a diet with UHT cream for 1 or 4 wk. The Ctl group was fed a UHT cream without additives, the Th group was fed a UHT cream that contained $\kappa$-carrageenan ( $\kappa-C G N ; 0.02 \%$ ), and the Th/Em group was fed a UHT cream that contained $\kappa$-CGN $(0.02 \%)$ and lactic acid esters of mono- and diglycerides $(0.1 \%)$. Assessment after 4 wk of the number of mucus cells per crypt in the (A) duodenum, (B) jejunum, and (C) ileum. (D) Representative photomicrographs of Alcian blue and periodic acid-Schiff'sstained jejunum. Original magnifications of intestine $\times 20$ and scale bars $=100 \mu \mathrm{m}$. Gene expression in the duodenum of (E) Muc2. (F) Ocln , and (G) Zo1 were quantified by real-time quantitative PCR. Results are expressed as means \pm SEM. Means without a common letter differ $(P$ $<0.05)$ : $(\mathrm{a}-\mathrm{c})$ after $1 \mathrm{wk}$ of diet, and $(\mathrm{x}-\mathrm{z})$ after $4 \mathrm{wk}$ of diet. Values are normalized to the levels of TBP mRNA. mMuc2 = mucin-2; ZO-1 = zonula occludens 1 ; TBP $=$ TATA-binding protein. Color version available online.

\section{Correlations Between Cream Properties and Metabolic Responses}

Among the physico-chemical parameters of creams modified by formulation (Table 3), whipped cream firmness was lower in Th/Em cream compared with the other creams and after 1 wk of diet, firmness was negatively correlated with the lipid absorption genes $(\mathrm{r}=-0.76, P<0.001$ with $M t t p, \mathrm{r}=-0.65, P<$ 0.001 with Fatp 4, and $\mathrm{r}=-0.61, P<0.01$ with Fabp2). Altogether, it is known that cream whipping time is decreased by additives. Regarding metabolic outcomes, the cream whipping time was negatively correlated with Mttp $(\mathrm{r}=-0.76, P<0.001)$ and Fatp $4(\mathrm{r}=-0.59, P$ 
$<0.005)$ and was lowest in Th/Em cream. An inverse correlation was observed between occludin and $Z \circ 1$ with the whipping time $(\mathrm{r}=-0.67, P<0.001$ for $Z \circ 1$, $\mathrm{r}=-0.66, P<0.001$ for occludin) and the firmness of the whipped cream $(\mathrm{r}=-0.74, P<0.001$ for $Z o 1, \mathrm{r}$ $=-0.67, P<0.001$ for occludin). In the colon, after $4 \mathrm{wk}$, we observed a positive correlation between the expression of gene involved in ER stress and the size of fat droplets/aggregates $\mathrm{d}_{4,3}$ water $(\mathrm{r}=0.81, P<0.001$ for Chop, $\mathrm{r}=0.56, P<0.01$ for Grp 78; Supplemental Table S2, https://doi.org/10.3168/jds.2018-14783).

\section{DISCUSSION}

The purpose of the present study was to evaluate the effect of different formulations of UHT cream at $35 \%$ fat. Usually, stabilizers/thickeners are used to increase the viscosity and stability of dairy cream (Koupantsis and Kiosseoglou, 2009). The major benefit of adding emulsifiers is to enhance the emulsified structure of creams and consequently their whipping ability, of particular interest for cooks. Carrageenans are the mostly used stabilizers in creams (Spagnuolo et al., 2005). In
A

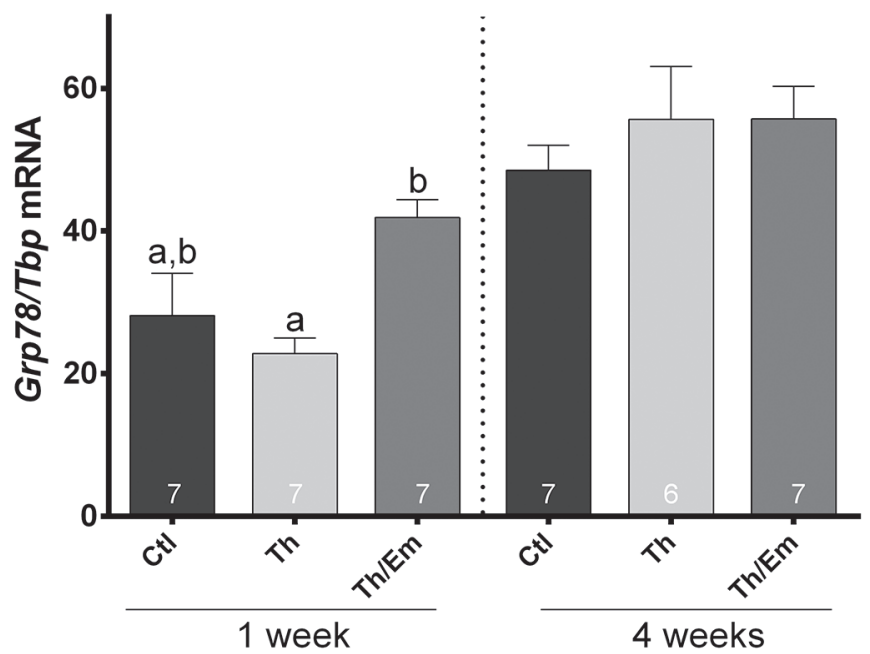

C

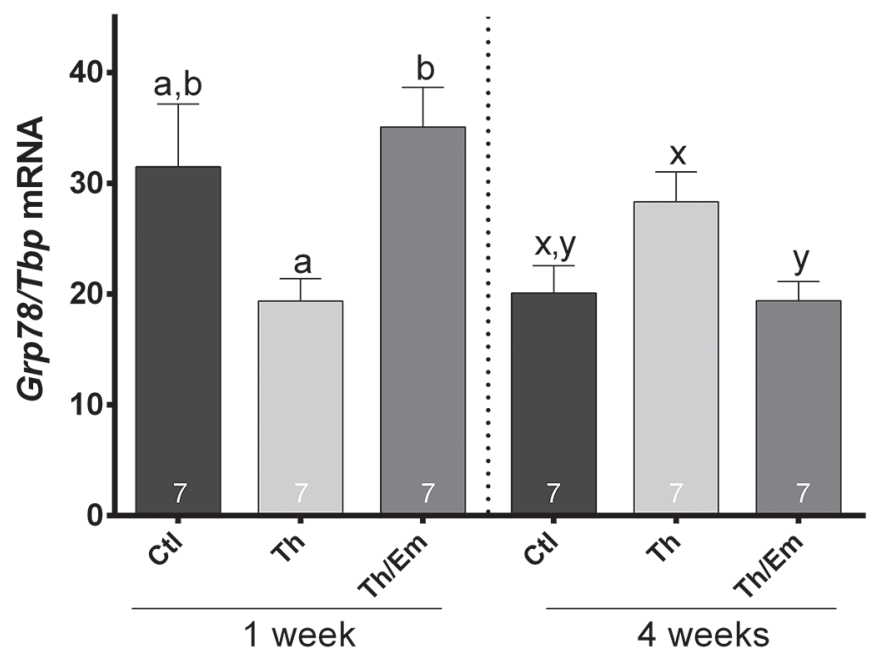

B

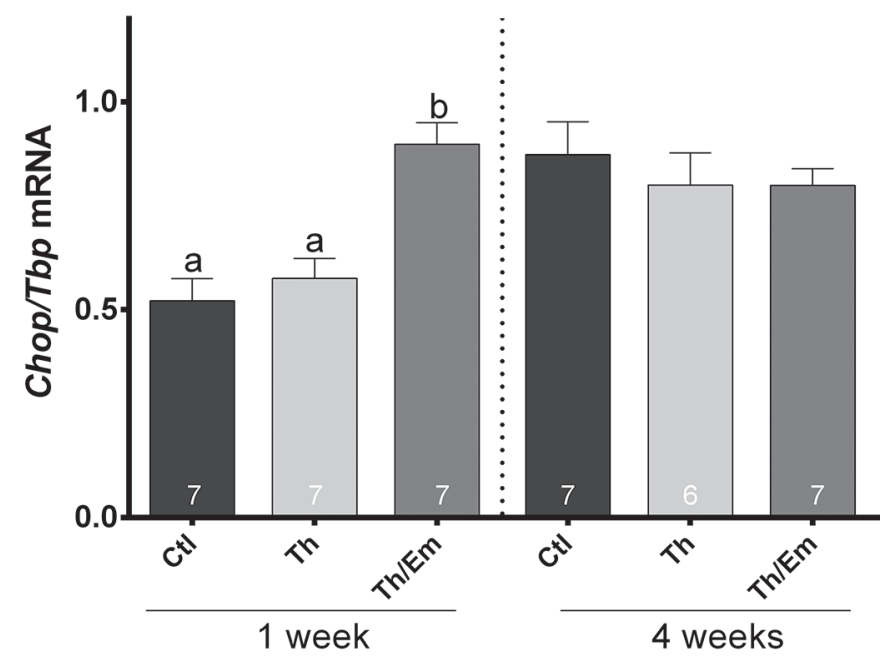

D

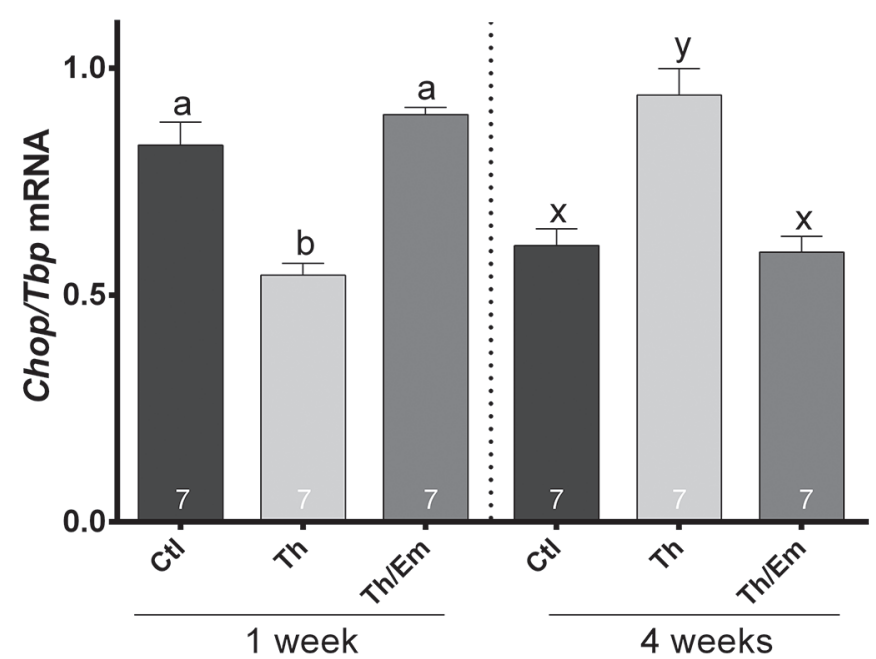

Figure 5. Intestinal expression of gene involved in the endoplasmic reticulum stress in duodenum and colon of mice fed a diet with UHT cream for 1 or $4 \mathrm{wk}$. The Ctl group fed a UHT cream without additives, the Th group was fed a UHT cream that contained $\kappa$-carrageenan ( $\kappa-\mathrm{CGN} ; 0.02 \%)$, and Th/Em group was fed a UHT cream that contained $\kappa$-CGN (0.02\%) and lactic acid esters of mono- and diglycerides $(0.1 \%)$. Real-time quantitative (q)PCR assay of mRNA levels of (A) glucose-related protein precursor 78 (Grp 78 ) and (B) proapoptotic C/EBP homologous protein (Chop) in the duodenum. qPCR assay of mRNA levels of (C) Grp r8 and (D) Chop in the colon. Data are shown as means \pm SEM. Means without a common letter differ $(P<0.05)$ : $(\mathrm{a}-\mathrm{c})$ after 1 wk of diet, and $(\mathrm{x}-\mathrm{z})$ after 4 wk of diet. 
Table 3. Main physico-chemical parameters of UHT creams modified by the addition of additives

\begin{tabular}{lccc}
\hline & \multicolumn{3}{c}{ Type of cream } \\
\cline { 2 - 4 } & Ctl & Th & Th/Em \\
\hline $\mathrm{Nhysico-chemical} \mathrm{parameter}^{1,2}$ & 3.0 & 5.6 & 3.4 \\
$\mathrm{~d}_{4,3}$ in water, $\mu \mathrm{m}$ & 1.0 & 2.1 & 1.2 \\
Flocculation index, unitless & 22 & 504.5 & 472.2 \\
Wiscosity at $4^{\circ} \mathrm{C}, \mathrm{cP}$ & 116 & 124.3 & 102.2 \\
Whipped cream firmness, unitless & 4.23 & 4 & 3.43 \\
Whipping time, min & &
\end{tabular}

${ }^{1}$ Uncertainty values of physico-chemical parameters: volume-weighted diameter $\left(\mathrm{d}_{4,3}\right)$ in water, $5 \%$; flocculation index, $5 \%$; viscosity $4{ }^{\circ} \mathrm{C}$, $10 \%$; whipped cream firmness, $10 \%$; whipping time, $10 \%$.

${ }^{2}$ For other physicochemical parameters, see Supplemental Table S3 (https://doi.org/10.3168/jds.2018-14783).

${ }^{3} \mathrm{Ctl}=$ UHT cream without additives; Th $=$ UHT cream with $\kappa$-carrageenan $(\kappa-\mathrm{CGN}) ; \mathrm{Th} / \mathrm{Em}=\mathrm{UHT}$ cream with $\kappa$-CGN and lactic acid esters of mono- and diglycerides.

this respect, $\mathrm{Th} / \mathrm{Em}$ cream in the present study is a standard cream present in supermarket shelfs (whereas the present control cream is devoid of additives); of note, some marketed creams correspond to the present Th cream (no emulsifiers) and can be processed with alternative heat treatment (such as direct steam injection, as previously studied regarding metabolic effects in mice, Milard et al., 2018). In this study, a cream was supplemented with thickener, CGN, and another cream with both thickener, CGN, and emulsifier, MAG/DAG esters. These additives could affect cream physicochemical characteristics and have different metabolic effects in mice.

In this study we observed a difference in mice liver weight after 1 wk of diet for the Th/Em group, which presented larger livers compared with the Th group. However, after $4 \mathrm{wk}$, we did not observe any deleterious effect of additives on liver damage score, which was even lower in Th/Em versus Ctl. Bhattaharyya et al. (2012) reported that exposure to undegraded CGN $(\lambda$ К) via drinking water for $18 \mathrm{~d}(50 \mu \mathrm{g} / \mathrm{d})$ induced (1) glucose intolerance and insulin resistance in C57BL/6J mice, and (2) inhibition of insulin signaling in the liver of the C57BL/6J mice and in HepG2 cells (Bhattacharyya et al., 2012). Here we observed no differences on insulin nor glucose concentrations in plasma after 7 to $28 \mathrm{~d}$ of diet despite higher CGN intake $(\sim 300 \mu \mathrm{g}$ of CGN/d). Maybe the type of CGN (only $\kappa$ here) and a food matrix effect (CGN pure in water in the former study, inside cream in pellets here) can explain a differential metabolic effect that would deserve further investigation.

Modification of hepatic response can be explained by differences in lipid metabolism. The presence of ER stress has been demonstrated in steatotic liver in rodents and humans (Ozcan et al., 2004; Puri et al.,
2008). This ER stress leads to significant disturbances of hepatic lipid metabolism, notably by activating SREB1c and reducing the secretion of ApoB, the apolipoprotein associated with TG-rich lipoproteins (Kammoun et al., 2009). Here we did not find any effect of cream formulation on the gene expression of $A p o B$ and Mttp in the liver between groups fed the different creams (results not shown). However, other changes in lipid metabolism may be responsible for hepatic effect. Indeed, FATP4-KO mice develop steatosis (Lenz et al., 2011). Here, after 1 wk of diet, the addition of emulsifier in the cream (Th/Em) induced a greater expression of Mttp, Fabp2, and Fatp 4 mRNA in the duodenum compared with the cream containing the thickener alone (Th); this may have contributed to the low liver damage score in this group. However, we did not observe differential effects between creams on lipid metabolism genes after $4 \mathrm{wk}$ of diet. Considering the time for complete renewal/turnover of the intestinal mucosa in mice (4-5 d) (Stappenbeck et al., 1998), we therefore hypothesize an adaptation of intestinal lipid metabolism to diets after an initial transition time between 1 and 4 wk (Figure 6). After 1 wk, the Th group tended to present higher fecal fatty acids than other groups albeit not significantly, whereas the fecal fatty acid loss was significantly lower in $\mathrm{Th}$ versus other groups after $4 \mathrm{wk}$. Because the Th cream presented the highest flocculation of fat droplets, this could have modulated lipid digestion at early stages of the dietary intervention (Armand et al., 1996; Bourlieu et al., 2015; Bourlieu and Michalski, 2015). Mechanisms leading to lower fecal fatty acids after 4 wk in this group could be related to a compensatory effect on lipid absorption metabolism between 1 and 4 wk (reflected by, e.g., gene expression of Mttp, Fatp 4, and Fabp2) and remain to be elucidated in detail, notably by characterizing cream droplet structure and lipolysis along the gut (Figure 6). Of note, additives had a dramatic effect on increasing cream viscosity, as expected, but cream viscosity was not correlated significantly with the studied intestinal and metabolic outcomes.

Food additives such as synthetic emulsifiers were reported to induce an increased intestinal permeability due to a defective mucosal barrier (Csaki, 2011; Chassaing et al., 2015; Singh et al., 2016). Moreover, incubation of physiologically degraded CGN on Caco-2 cells $(0.5,0.05$, or $0.005 \mathrm{mg} / \mathrm{mL})$ results in tight junction dissociation and impaired epithelial cell structure (Fahoum et al., 2017). Here we analyzed the effect of cream additives on tight junctions in the intestine and on number of mucus cells. There was a stronger expression of occludin and Zo1 after 1 wk with Th/Em cream but no difference among groups after 4 wk. However, we observed more mucus cells in duodenum, jejunum, 
and ileum after 4 wk in the Th/Em group. The proportion of mucus cells in the epithelium of the duodenum is typically 10 to $15 \%$ (Forstner and Forstner, 1994) of the total population and rises in the colon (Cheng et al., 1984; Forstner and Forstner, 1994). Mucin 2, isolated by Gum et al. (1989), is the main mucin secreted. The Th group had a lower expression of Muc2 despite the same mucus cell number as the Ctl group. Modifications of mucus cells, MUC2 production, and tight junction protein expression have been reported in various intestinal and systemic pathologies (Einerhand et al., 2002; Van der Sluis et al., 2006). For example, ulcerative colitis, a chronic inflammatory disease of the intestine, is associated with a decrease in the number of mucus cells and the production of MUC2 (Dorofeyev et al., 2013). Model of mice genetically deficient in MUC2 developed colitis and colorectal tumors (Velcich et al., 2002; Van der Sluis et al., 2006), with these results suggesting the importance of goblet cells/MUC2. The main role of mucus gel and mucins is to physically protect the intestine by lubricating the wall. Altogether, the positive effect of both CGN and MAG/DAG esters on gene expression of tight junctions after 1 wk and on the number of mucus cells in the small intestine after $4 \mathrm{wk}$ can be considered as a favorable effect. Some free fatty acids have been described to modulate mucus cell number (Benoit et al., 2015). Whether MAG/DAG in the small intestinal mucosa could directly induce such effects should now be investigated.

Among the physico-chemical parameters of the creams modified by the formulation, the cream having a higher fat droplet flocculation (Th) can potentially be digested more slowly and subjected to a longer and less efficient gastric emptying. This can explain why, in the short term, the lipid metabolism genes are less expressed in comparison with the group fed cream containing both additives and having a lower firmness and lower flocculation. Indeed, emulsified fat structure is known to modulate lipid digestion and absorption (Armand et al., 1996; Bourlieu et al., 2015; Bourlieu and Michalski, 2015).

After 1 wk of diet, a higher expression of Grp 78 and Chop, involved in ER stress, was observed in the duodenum with $\mathrm{Th} / \mathrm{Em}$ in comparison with $\mathrm{Th}$ and

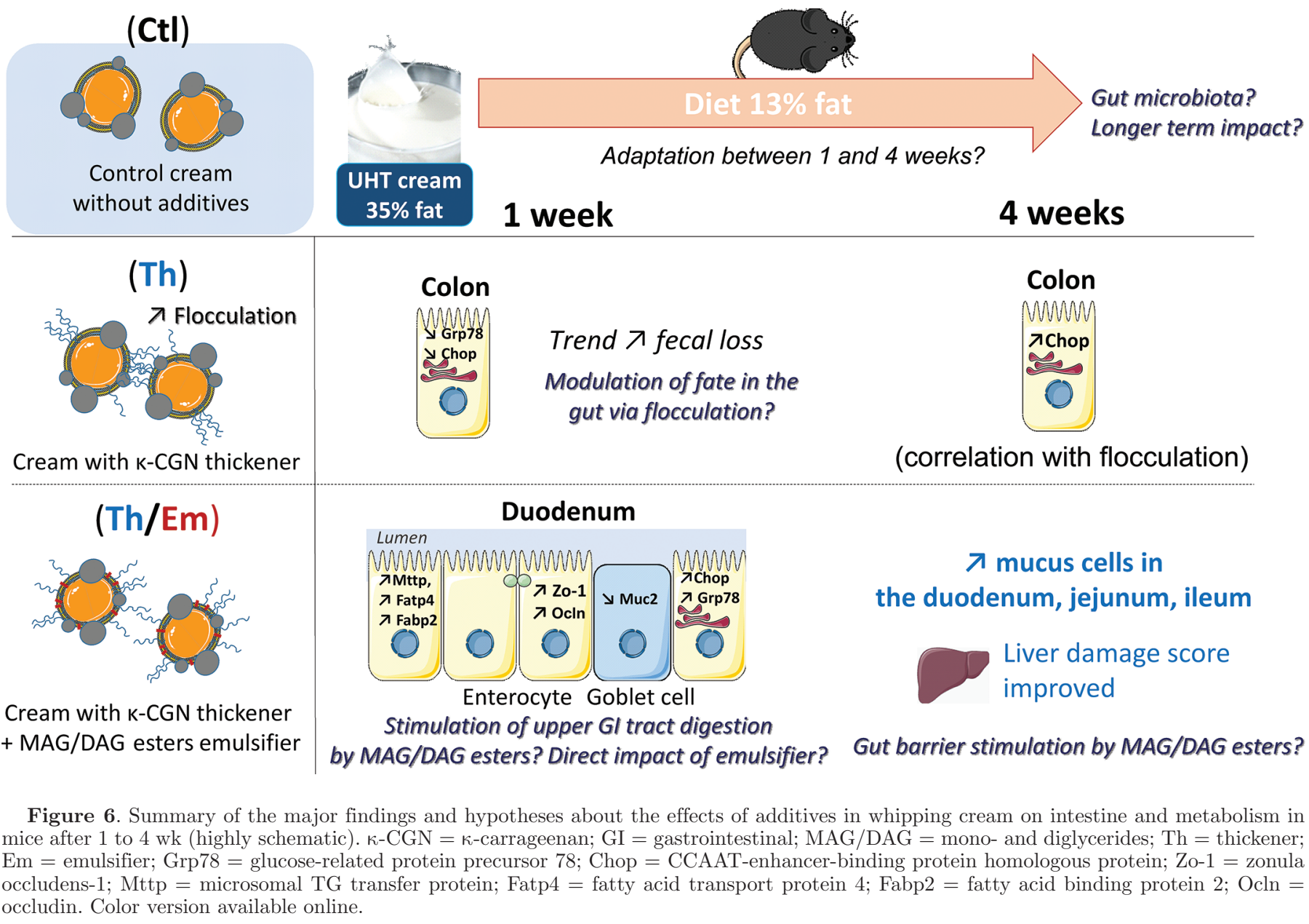


Ctl, whereas in the colon it was not different in $\mathrm{Th} /$ Em versus Ctl. Deregulation of synthesis and folding of secretory proteins can be explained by perturbations of ER homeostasis (Oyadomari and Mori, 2004). Furthermore, intestinal secretory cells, such as goblet cells, require unaltered ER function for the production of cell-surface mucins (Luo and Cao, 2015). Here, after 1 wk the Th/Em group retained apparently unaltered mucus cell metabolism despite this higher expression of ER stress markers. Moreover, no differences among groups were observed in the ER stress genes in the duodenum after $4 \mathrm{wk}$ of diet. However, after $4 \mathrm{wk}$ in the colon, the ER stress gene expression increased in the Th group, notably for Chop. This is consistent with an in vitro study showing that CGN can increase CHOP expression in hepatic HepG2 cells (Jung et al., 2014). Importantly, increased colonic expression of CHOP was described in colitis and can be reversed by dietary compounds (Sreedhar et al., 2015; Li et al., 2016; Bibi et al., 2017). We note here a correlation at 4 wk between the size of fat droplet aggregates of creams and the gene expression of Grp78 and Chop, markers of ER stress; therefore, different lipid residues in the colon according to different cream aggregates could have contributed to modulated ER stress in the colon (Figure 6). The longer-term intestinal effect of Th cream should thus be investigated. However, such an effect was not observed with $\mathrm{Th} / \mathrm{Em}$ cream in which CGN were associated with MAG/DAG esters. This suggests a matrix effect regarding interactions between additives that should also be further investigated.

Among studies about additives in mice, 1.0\% (wt/ vol) of the emulsifier polysorbate- 80 or stabilizer carboxymethylcellulose, via drinking water for $12 \mathrm{wk}$, promoted colitis in mice predisposed to this disorder associated with altered microbiota composition (Chassaing et al., 2015). Most recently, C57Bl/6J mice fed glycerol-monolaurate at $0.015 \%$ in a low-fat diet for 8 wk developed metabolic syndrome, gut microbiota dysbiosis, and systemic low-grade inflammation (Jiang et al., 2018). However, glycerol-monolaurate is a 12-carbon-fatty acid monoglyceride contrary to our study where we focused on the effect of lactic acid esters of MAG and DAG containing 16 and 18 carbons; moreover, we designed diets of higher fat content and studied shorter term adaptations of metabolism. Therefore, the longer-term effect of MAG/DAG esters and CGN in cream should now be elucidated as well as their relative effect according to the matrix (in water or in cream or in other types of lipids/foods).

Whether CGN can have deleterious effects has been extensively studied in the literature (Tobacman, 2001). These have often been administered in drinking water at concentrations greater than $1 \%$. Studies showed that
CGN magnify existing intestinal inflammation (Watt and Marcus, 1971, 1973; Onderdonk et al., 1977; Wei et al., 2016). It is important to highlight that cases of CGN-induced ulcerative colitis appeared to be present in rodents and were not confirmed in monkeys or humans (Corpet et al., 1997). Therefore, the present results on intestinal ER stress should be confirmed in other models and in humans. Furthermore, the CGN type ( $\kappa$-CGN, $\lambda$-CGN, and $\iota-C G N)$ must be taken into account. Indeed, Fahoum et al. (2017) recently studied the effect between the various CGN types using an in vitro human digestion model and Caco-2 cells. The type of CGN affected gastric proteolysis of food protein in the in vitro human digestion model. No significant differences were observed on Caco-2 permeability and CXCR1 expression (an inflammatory marker) with physiologically degraded $\kappa$-CGN (the type of CGN used in the present study) contrary to $\lambda$ - and -CGN that increased these markers (Fahoum et al., 2017). Moreover, a production of tumor necrosis factor $\alpha$ has been observed in human monocyte with degraded -CGN, and $5 \%(\mathrm{wt} / \mathrm{vol})$ of $\mathrm{\iota -CGN}$ in the drinking water for 55 d causes colitis in rats (Benard et al., 2010). Furthermore, exposure to a small dose of $\lambda$-CGN, $\kappa$-CGN, and $\iota$-CGN $(1 \mu \mathrm{g} / \mathrm{mL})$ was reported to activate Bcl110 and induces an inflammatory cascade in normal colonic epithelial cells resulting in a production of proinflammatory cytokine IL-8 (Borthakur et al., 2007). The role of CGN and carboxymethylcellulose in the development of intestinal inflammation was therefore reviewed and discussed (Martino et al., 2017). Here, Th cream, formulated with $\kappa$-CGN alone $(0.02 \%$ in cream, i.e., 8 $\mathrm{mg} / 100 \mathrm{~g}$ of diet), did not induce any inflammatory effect on adipose tissue or circulating parameters in the short term despite higher colonic ER stress; longer term studies are now required.

Regarding other possible mechanisms of CGN effect, a promoting effect on colon tumorigenesis was reported (Arakawa et al., 1988), which was probably due to alterations of the gut microbiota (Arakawa et al., 1986). A recent study demonstrated that all carrageenans had toxic effects in the colon of C57BL/6J mice and induced colitis by the loss of Akkemansia muciniphila, an anti-inflammatory bacterium in the gut (Shang et al., 2017). Moreover, the cecal ulcerations observed in response to degraded CGN in guinea pigs (Onderdonk et al., 1977) were not observed in germ-free guinea pigs (Onderdonk et al., 1978). Altogether, the onset of inflammation is now largely reported to be associated with gut microbiota (Arakawa et al., 1986; Martino et al., 2017). Unfortunately, gut microbiota could not be analyzed in the present study, but our results provide incentive to analyze how it is affected by additives in dairy in a follow-up protocol. 
Altogether, the cream enriched with $\kappa$-CGN only presented the largest aggregates, highest flocculation index, and highest viscosity: an effect of these parameters on the lower expression of some genes in the intestine thus deserves to be further elucidated. The present study tested the effect of these additives in the real dairy matrix in which they are usually incorporated, with an aim to be realistic. Our strategy can explain some differential effects compared with other published studies that used higher doses or simple dilution of the additives in water. This provides incentive to further elucidate the relative effect of food additives according to different food matrixes. Notably, the long-term effects of intestinal ER stress, and the effect of additives on gut microbiota, now deserve to be studied to evaluate the effect of different dairy formulations on the intestinal barrier and the hepatic and metabolic effects. The interaction between different additives should also be considered, as here the effect of $\kappa$-CGN in cream was different when it was the sole additive or associated with MAG/DAG esters. Rodent model results should also be confirmed by dietary intervention trials in humans to confirm whether additives used in food formulation affect human metabolism. As pointed out in a recent review (David et al., 2018), the use of CGN is highly controversial and further studies are needed to determine their effect on human health and disease.

\section{CONCLUSIONS}

In this study, the effects of short-term cream-enriched diets in mice demonstrated that combined $\kappa$-CGN and MAG/DAG ester additives in UHT cream increased the mucus cell population and some markers of the intestinal barrier (occludin, Zo-1, and Muc2), and did not alter liver damage score, or even improved it (Th/Em), which would deserve confirmation in longer term studies. Altogether, the study of the health effect of food additives must be carefully evaluated in their target foods to combine the improvement of food organoleptic properties with a nondeleterious effect on health.

\section{ACKNOWLEDGMENTS}

This study was funded by Sodiaal-Candia R\&D. The authors thank CellImaP (Plateforme d'imagerie cellulaire, Federative Structure for Research 100, Dijon, France) for facilities in histological techniques and Dominique Martel (SAFE, Augy, France) for his assistance in diet formulation. We thank Armelle Penhoat (CarMeN Laboratory, Villeurbanne, France) for fruitful discussions, Véronique Pierre (CarMeN Laboratory) for assistance in diet preparation, and the Functional Lipidomics Plaform of IMBL (Institut Multidisciplinaire de
Biochimie des Lipides, Villeurbanne, France) for assistance in fatty acid analyses. We thank Gaëlle Pineau (CarMeN Laboratory) and Alexandre Debain (INSA, Villeurbanne, France) for their help with the animal study. S. Serieye and S. Bugeat are employees of Sodiaal-Candia R\&I (Research and Innovation Department, Paris, France). M. C. Michalski (CarMeN Laboratory) received other research funding from Sodiaal-Candia R\&I, CNIEL (the French Dairy Interbranch Organization, Paris, France), and Nutricia Research (Utrecht, the Netherlands) and has consulting activities for food and dairy companies. These activities had no link with the present study. Other authors declared no conflict of interest.

\section{REFERENCES}

Arakawa, S., M. Ito, and S. Tejima. 1988. Promoter function of carrageenan on development of colonic tumors induced by 1,2-dimethylhydrazine in rats. J. Nutr. Sci. Vitaminol. (Tokyo) 34:577-585.

Arakawa, S., M. Okumura, S. Yamada, M. Ito, and S. Tejima. 1986. Enhancing effect of carrageenan on the induction of rat colonic tumors by 1,2-dimethylhydrazine and its relation to beta-glucuronidase activities in feces and other tissues. J. Nutr. Sci. Vitaminol. (Tokyo) 32:481-485.

Arltoft, D., R. Ipsen, F. Madsen, and J. Vries. 2007. Interactions between carrageenans and milk proteins: A microstructural and rheological study. Biomacromolecules 8:729-736.

Armand, M., P. Borel, B. Pasquier, C. Dubois, M. Senft, M. Andre, J. Peyrot, J. Salducci, and D. Lairon. 1996. Physicochemical characteristics of emulsions during fat digestion in human stomach and duodenum. Am. J. Physiol. 271:G172-G183.

Benard, C., A. Cultrone, C. Michel, C. Rosales, J. P. Segain, M. Lahaye, J. P. Galmiche, C. Cherbut, and H. M. Blottiere. 2010. Degraded carrageenan causing colitis in rats induces TNF secretion and ICAM-1 upregulation in monocytes through NF-kappaB activation. PLoS One 5:e8666.

Benoit, B., J. Bruno, F. Kayal, M. Estienne, C. Debard, R. Ducroc, and P. Plaisancie. 2015. Saturated and unsaturated fatty acids differently modulate colonic goblet cells in vitro and in rat pups. J. Nutr. 145:1754-1762.

Benoit, B., P. Plaisancie, A. Geloen, M. Estienne, C. Debard, E. Meugnier, E. Loizon, P. Daira, J. Bodennec, O. Cousin, H. Vidal, F. Laugerette, and M. C. Michalski. 2014. Pasture v. standard dairy cream in high-fat diet-fed mice: Improved metabolic outcomes and stronger intestinal barrier. Br. J. Nutr. 112:520-535.

Bhattacharyya, S., I. O-Sullivan, S. Katyal, T. Unterman, and J. K. Tobacman. 2012. Exposure to the common food additive carrageenan leads to glucose intolerance, insulin resistance and inhibition of insulin signalling in HepG2 cells and C57BL/6J mice. Diabetologia 55:194-203.

Bhattacharyya, S., A. Borthakur, P. K. Dudeja, and J. K. Tobacman. 2008. Carrageenan induces cell cycle arrest in human intestinal epithelial cells in vitro. J. Nutr. 138:469-475.

Bibi, S., L. F. de Sousa Moraes, N. Lebow, and M. J. Zhu. 2017. Dietary green pea protects against DSS-induced colitis in mice challenged with high-fat diet. Nutrients 9.

Borthakur, A., S. Bhattacharyya, P. K. Dudeja, and J. K. Tobacman. 2007. Carrageenan induces interleukin- 8 production through distinct Bcl10 pathway in normal human colonic epithelial cells. Am. J. Physiol. Gastrointest. Liver Physiol. 292:G829-G838.

Bourlieu, C., K. Bouzerzour, S. Ferret-Bernard, C. Le Bourgot, S. Chever, O. Ménard, A. Deglaire, I. Cuinet, P. Le Ruyet, C. Bonjhomme, D. Dupont, and Le-Huërou-Luron.. 2015. Infant formula interface and fat source impact on neonatal digestion and gut microbiota. Eur. J. Lipid Sci. Technol. 117:1500-1512. 
Bourlieu, C., and M. C. Michalski. 2015. Structure-function relationship of the milk fat globule. Curr. Opin. Clin. Nutr. Metab. Care $18: 118-127$.

Burges Watson, D. 2008. Public health and carrageenan regulation: A review and analysis. J. Appl. Phycol. 20:505-513.

Chassaing, B., O. Koren, J. K. Goodrich, A. C. Poole, S. Srinivasan, R. E. Ley, and A. T. Gewirtz. 2015. Dietary emulsifiers impact the mouse gut microbiota promoting colitis and metabolic syndrome. Nature 519:92-96.

Cheng, H., M. Bjerknes, and J. Amar. 1984. Methods for the determination of epithelial cell kinetic parameters of human colonic epithelium isolated from surgical and biopsy specimens. Gastroenterology 86:78-85.

Choi, H. J., J. Kim, S. H. Park, K. H. Do, H. Yang, and Y. Moon. 2012. Pro-inflammatory NF-kappaB and early growth response gene 1 regulate epithelial barrier disruption by food additive carrageenan in human intestinal epithelial cells. Toxicol. Lett. 211:289-295.

Corpet, D. E., S. Tache, and M. Preclaire. 1997. Carrageenan given as a jelly, does not initiate, but promotes the growth of aberrant crypt foci in the rat colon. Cancer Lett. 114:53-55.

Csaki, K. F. 2011. Synthetic surfactant food additives can cause intestinal barrier dysfunction. Med. Hypotheses 76:676-681.

David, S., C. Shani Levi, L. Fahoum, Y. Ungar, E. G. Meyron-Holtz, A. Shpigelman, and U. Lesmes. 2018. Revisiting the carrageenan controversy: Do we really understand the digestive fate and safety of carrageenan in our foods? Food Funct.9:1344-1352.

de Oliveira Otto, M. C., D. Mozaffarian, D. Kromhout, A. G. Bertoni, C. T. Sibley, D. R. Jacobs, and J. A. Nettleton. 2012. Dietary intake of saturated fat by food source and incident cardiovascular disease: The multi-ethnic study of atherosclerosis. Am. J. Clin. Nutr. 96:397-404.

Dorofeyev, A. E., I. V. Vasilenko, O. A. Rassokhina, and R. B. Kondratiuk. 2013. Mucosal barrier in ulcerative colitis and Crohn's disease. Gastroenterol. Res. Pract. 2013:431231.

Drouin-Chartier, J.-P., D. Brassard, M. Tessier-Grenier, J. A. Côté, M.-E. Labonté, S. Desroches, P. Couture, and B. Lamarche. 2016a. Systematic review of the association between dairy product consumption and risk of cardiovascular-related clinical outcomes. Adv. Nutr. 7:1026-1040.

Drouin-Chartier, J. P., J. A. Cote, M. E. Labonte, D. Brassard, M. Tessier-Grenier, S. Desroches, P. Couture, and B. Lamarche. 2016b. Comprehensive review of the impact of dairy foods and dairy fat on cardiometabolic risk. Adv. Nutr. 7:1041-1051.

Einerhand, A. W., I. B. Renes, M. K. Makkink, M. van der Sluis, H. A. Buller, and J. Dekker. 2002. Role of mucins in inflammatory bowel disease: Important lessons from experimental models. Eur. J. Gastroenterol. Hepatol. 14:757-765.

Engster, M., and R. Abraham. 1976. Cecal response to different molecular weights and types of carrageenan in the guinea pig. Toxicol. Appl. Pharmacol. 38:265-282.

Fahoum, L., A. Moscovici, S. David, R. Shaoul, G. Rozen, E. G. Meyron-Holtz, and U. Lesmes. 2017. Digestive fate of dietary carrageenan: Evidence of interference with digestive proteolysis and disruption of gut epithelial function. Mol. Nutr. Food Res. 61.

Forstner, J., and G. Forstner. 1994. Gastrointestinal mucus. Pages 1255-1283 in Physiology of the Gastrointestinal Tract. Raven Press, New York, NY.

Gum, J. R., J. C. Byrd, J. W. Hicks, N. W. Toribara, D. T. Lamport, and Y. S. Kim. 1989. Molecular cloning of human intestinal mucin cDNAs. Sequence analysis and evidence for genetic polymorphism. J. Biol. Chem. 264:6480-6487.

Jiang, Z., M. Zhao, H. Zhang, Y. Li, M. Liu, and F. Feng. 2018. Antimicrobial emulsifier-glycerol monolaurate induces metabolic syndrome, gut microbiota dysbiosis and systemic low-grade inflammation in low-fat diet fed mice. Mol. Nutr. Food Res. 62. https://doi .org/10.1002/mnfr.201700547.

Jung, T. W., S. Y. Lee, H. C. Hong, H. Y. Choi, H. J. Yoo, S. H. Baik, and K. M. Choi. 2014. AMPK activator-mediated inhibition of endoplasmic reticulum stress ameliorates carrageenan-induced insulin resistance through the suppression of selenoprotein $\mathrm{P}$ in HepG2 hepatocytes. Mol. Cell. Endocrinol. 382:66-73.
Kamel, B. S. 1991. Emulsifiers. In Food Additive User's Handbook. J. Smith, ed. Springer, Boston, MA.

Kammoun, H. L., H. Chabanon, I. Hainault, S. Luquet, C. Magnan, T. Koike, P. Ferre, and F. Foufelle. 2009. GRP78 expression inhibits insulin and ER stress-induced SREBP-1c activation and reduces hepatic steatosis in mice. J. Clin. Invest. 119:1201-1215.

Koupantsis, T., and V. Kiosseoglou. 2009. Whey protein-carboxymethylcellulose interaction in solution and in oil-in-water emulsion systems. Effect on emulsion stability. Food Hydrocoll. 23:11561163.

Lal, S. N., C. J. O'Connor, and L. Eyres. 2006. Application of emulsifiers/stabilizers in dairy products of high rheology. Adv. Colloid Interface Sci. 123-126:433-437.

Lenz, L. S., J. Marx, W. Chamulitrat, I. Kaiser, H. J. Grone, G. Liebisch, G. Schmitz, C. Elsing, B. K. Straub, J. Fullekrug, W. Stremmel, and T. Herrmann. 2011. Adipocyte-specific inactivation of Acyl-CoA synthetase fatty acid transport protein 4 (Fatp4) in mice causes adipose hypertrophy and alterations in metabolism of complex lipids under high fat diet. J. Biol. Chem. 286:3557835587.

Li, B., A. Zani, C. Lee, E. Zani-Ruttenstock, Z. Zhang, X. Li, W. Ip, T. Gonska, and A. Pierro. 2016. Endoplasmic reticulum stress is involved in the colonic epithelium damage induced by maternal separation. J. Pediatr. Surg. 51:1001-1004.

Lovegrove, J. A., and D. I. Givens. 2016. Dairy food products: Good or bad for cardiometabolic disease? Nutr. Res. Rev. 29:249-267.

Luo, K., and S. S. Cao. 2015. Endoplasmic reticulum stress in intestinal epithelial cell function and inflammatory bowel disease. Gastroenterol. Res. Pract. 2015:328791.

Martino, J. V., J. Van Limbergen, and L. E. Cahill. 2017. The role of carrageenan and carboxymethylcellulose in the development of intestinal inflammation. Front Pediatr. 5:96.

Milard, M., F. Laugerette, S. Bugeat, P. Plaisancié, M. Létisse, E. Meugnier, E. Loizon, A. Durand, C. Buisson, A. Géloën, S. Serieye, and M.-C. Michalski. 2018. Metabolic effects in mice of cream processing: Direct ultra-high-temperature process lowers high-fatinduced adipose tissue inflammation. J. Dairy Sci. 101:1063610648. https://doi.org/10.3168/jds.2018-14782.

Mir, H., A. S. Meena, K. K. Chaudhry, P. K. Shukla, R. Gangwar, B. Manda, M. K. Padala, L. Shen, J. R. Turner, P. Dietrich, I. Dragatsis, and R. Rao. 2016. Occludin deficiency promotes ethanol-induced disruption of colonic epithelial junctions, gut barrier dysfunction and liver damage in mice. Biochim. Biophys. Acta 1860:765-774.

Onderdonk, A. B., J. A. Hermos, and J. G. Bartlett. 1977. The role of the intestinal microflora in experimental colitis. Am. J. Clin. Nutr. $30: 1819-1825$

Onderdonk, A. B., J. A. Hermos, J. L. Dzink, and J. G. Bartlett. 1978. Protective effect of metronidazole in experimental ulcerative colitis. Gastroenterology 74:521-526.

Oosting, A., N. van Vlies, D. Kegler, L. Schipper, M. AbrahamseBerkeveld, S. Ringler, H. J. Verkade, and E. M. van der Beek. 2014. Effect of dietary lipid structure in early postnatal life on mouse adipose tissue development and function in adulthood. Br. J. Nutr. 111:215-226.

Oyadomari, S., and M. Mori. 2004. Roles of CHOP/GADD153 in endoplasmic reticulum stress. Cell Death Differ. 11:381-389.

Ozcan, U., Q. Cao, E. Yilmaz, A. H. Lee, N. N. Iwakoshi, E. Ozdelen, G. Tuncman, C. Gorgun, L. H. Glimcher, and G. S. Hotamisligil. 2004. Endoplasmic reticulum stress links obesity, insulin action, and type 2 diabetes. Science 306:457-461.

Puri, P., F. Mirshahi, O. Cheung, R. Natarajan, J. W. Maher, J. M. Kellum, and A. J. Sanyal. 2008. Activation and dysregulation of the unfolded protein response in nonalcoholic fatty liver disease. Gastroenterology 134:568-576.

Rosqvist, F., A. Smedman, H. Lindmark-Mansson, M. Paulsson, P. Petrus, S. Straniero, M. Rudling, I. Dahlman, and U. Riserus. 2015. Potential role of milk fat globule membrane in modulating plasma lipoproteins, gene expression, and cholesterol metabolism in humans: A randomized study. Am. J. Clin. Nutr. 102:20-30. 
Shang, Q., W. Sun, X. Shan, H. Jiang, C. Cai, J. Hao, G. Li, and G. Yu. 2017. Carrageenan-induced colitis is associated with decreased population of anti-inflammatory bacterium, Akkermansia muciniphila, in the gut microbiota of C57BL/6J mice. Toxicol. Lett. 279:87-95.

Singh, R. K., N. Wheildon, and S. Ishikawa. 2016. Food additive P-80 impacts mouse gut microbiota promoting intestinal inflammation, obesity and liver dysfunction. SOJ Microbiol. Infect. Dis. 4.

Spagnuolo, P. A., D. G. Dalgleish, H. D. Goff, and E. R. Morris. 2005. Kappa-carrageenan interactions in systems containing casein micelles and polysaccharide stabilizers. Food Hydrocoll. 19:371-377.

Sreedhar, R., S. Arumugam, R. A. Thandavarayan, V. V. Giridharan, V. Karuppagounder, V. Pitchaimani, R. Afrin, M. Harima, T. Nakamura, K. Ueno, M. Nakamura, K. Suzuki, and K. Watanabe. 2015. Toki-shakuyaku-san, a Japanese kampo medicine, reduces colon inflammation in a mouse model of acute colitis. Int. Immunopharmacol. 29:869-875.

Stappenbeck, T. S., M. H. Wong, J. R. Saam, I. U. Mysorekar, and J. I. Gordon. 1998. Notes from some crypt watchers: Regulation of renewal in the mouse intestinal epithelium. Curr. Opin. Cell Biol. 10:702-709

Thorning, T. K., H. C. Bertram, J. P. Bonjour, L. de Groot, D. Dupont, E. Feeney, R. Ipsen, J. M. Lecerf, A. Mackie, M. C. McKinley, M. C. Michalski, D. Remond, U. Riserus, S. S. SoedamahMuthu, T. Tholstrup, C. Weaver, A. Astrup, and I. Givens. 2017. Whole dairy matrix or single nutrients in assessment of health effects: Current evidence and knowledge gaps. Am. J. Clin. Nutr. 105:1033-1045.

Thorning, T. K., A. Raben, N. T. Bendsen, H. H. Jørgensen, P. Kiilerich, Y. Ardö, J. K. Lorenzen, K. Kristiansen, and A. Astrup.
2016. Importance of the fat content within the cheese-matrix for blood lipid profile, faecal fat excretion, and gut microbiome in growing pigs. Int. Dairy J. 61:67-75.

Tobacman, J. K. 2001. Review of harmful gastrointestinal effects of carrageenan in animal experiments. Environ. Health Perspect. 109:983-994

Van der Sluis, M., B. A. De Koning, A. C. De Bruijn, A. Velcich, J. P. Meijerink, J. B. Van Goudoever, H. A. Buller, J. Dekker, I. Van Seuningen, I. B. Renes, and A. W. Einerhand. 2006. Muc2deficient mice spontaneously develop colitis, indicating that MUC2 is critical for colonic protection. Gastroenterology 131:117-129.

Velcich, A., W. Yang, J. Heyer, A. Fragale, C. Nicholas, S. Viani, R. Kucherlapati, M. Lipkin, K. Yang, and L. Augenlicht. 2002. Colorectal cancer in mice genetically deficient in the mucin Muc2. Science 295:1726-1729.

Viennois, E., D. Merlin, A. T. Gewirtz, and B. Chassaing. 2017. Dietary emulsifier-induced low-grade inflammation promotes colon carcinogenesis. Cancer Res. 77:27-40.

Watanabe, K., B. S. Reddy, C. Q. Wong, and J. H. Weisburger. 1978. Effect of dietary undegraded carrageenan on colon carcinogenesis in F344 rats treated with azoxymethane or methylnitrosourea. Cancer Res. 38:4427-4430.

Watt, J., and R. Marcus. 1971. Carrageenan-induced ulceration of the large intestine in the guinea pig. Gut 12:164-171.

Watt, J., and R. Marcus. 1973. Experimental ulcerative disease of the colon in animals. Gut 14:506-510.

Wei, W., W. Feng, G. Xin, N. Tingting, Z. Zhanghe, C. Haimin, and Y. Xiaojun. 2016. Enhanced effect of kappa-carrageenan on TNBS-induced inflammation in mice. Int. Immunopharmacol. 39:218-228. 